Unio. Below Eik is a shallow depression which was once clearly a small lake and is even now swampy during the rainy season. Fragments of glass bangles from the ruins were kindly determined by Mr. R. L. Hobson of the British Museum to be of Arab manufacture of the fifteenth century or later. The obvious inference is that desiccation has proceeded rapidly during the last 500 years, although at present the doubt must remain whether the shells were brought from elsewhere for domestic purposes. No mussel shells, however, were found in four other similar ruins examined, a point in favour of their former habitat being Eik.

It may be added that no doubt can exist that a survey dealing with the Pleistocene geology of Somaliland, and including the Northern Frontier Province of Kenya, would provide results of no small scientific interest, especially if archæological work were undertaken at the same time.

The Athenæum,

JoHN PARKINSON.

Pall Mall, s.W.1, May 5.

1 Nature, 129, 651, April 30, 1932

2 Ann. Mag. Nat. Hist., Ser. 10, 8, p. 322.

\section{Specific Heat of Gases at High Temperatures}

EVIDENCE has been accumulating in my laboratory that combustion is in general far from being complete at the moment of maximum pressure in closed vessel gaseous explosions even under the best experimental conditions, and that consequently specific heat values for gases at high temperatures determined by the explosion method are much larger than the true values. Much of this evidence has rested upon certain assumptions, such, for example, as that the specific heats of various diatomic gases constituting the diluents in explosive mixtures are practically the same over any given temperature range. ${ }^{1}$ But recently Messrs. J. R. Brown and A. H. El Din have completed a carefully conducted and extended series of experiments which seem to offer conclusive proof that incomplete combustion at the moment of attainment of maximum pressure in closed vessel explosions is generally so large as to make the explosion method as usually employed unreliable for specific heat determinations.

In these experiments, mixtures of identical composition were exploded in two spherical vessels of different sizes-one 6 inches in diameter and the other 18 inches. Both pressures and heat losses during the explosion period were measured in each vessel. It was found that higher pressures were developed in the larger vessel than in the smaller vessel, and that these higher pressures were not to be explained to any very considerable extent in terms of smaller relative heat losses in the large vessel. The conclusion seems irresistible that combustion is more complete in the larger vessel than in the smaller one, due possiblyat any rate, in part - to the fact that as the time of explosion is greater in the larger vessel, combustion is in a more advanced phase.

Taking the data from one typical experiment in which the explosive mixture was an over-rich carbon monoxide air mixture at atmospheric density, it was found by the usual method of calculation that the apparent specific heat of carbon dioxide over the temperature range of the explosion, after allowing for the measured heat loss, was 15.55 for the small vessel (temperature range $20^{\circ}-1920^{\circ}$ C.) and 14.4 for the larger vessel $\left(20^{\circ}-1990^{\circ}\right.$ C. $)$. The values for the specific heats of carbon dioxide over these temperature ranges, as given by Partington and Shilling, are $9 \cdot 75$ and 9.81 respectively, and these are in all proba- bility nearer to the true values than those yielded by the explosions. The inference, then, is that while combustion is more complete in the large vessel than in the smaller one, it is seriously incomplete in both vessels.

Hydrogen explosions in the two vessels yielded apparent specific heats for steam which differ to much the same extent as those for carbon dioxide, but they are nearer to the Partington and Shilling values. An over-rich hydrogen mixture, for example, vielded apparent specific heat values of 10.7 for the smaller vessel $\left(20^{\circ}-1920^{\circ} \mathrm{C}\right.$.) and 9.5 for the larger vessel $\left(20^{\circ}-1985^{\circ} \mathrm{C}\right.$.). The values given by Partington and Shilling for these temperature ranges are $8 \cdot 4$ and $8 \cdot 54$.

Engineering Department,

The University, Leeds, May 24.

1 Thorp, Phil. Mag., Dec. 1929, p. 829.

\section{Relative Excitation of the Three X-ray $L$-Levels} with Gathode Rays of Different Velocities

SkINNER, Robinson, and others have studied the relative excitation of the three X-ray levels $L_{\mathrm{III}}, L_{\mathrm{II}}$, and $L_{\mathrm{I}}$, when for this excitation primary radiation of different wave-length is used. Such experiments may be done by studying the relative intensity of the emission lines which combine with each of the three $L$-levels (Skinner) or by an estimation of the relative intensity of the secondary $\beta$-rays which emerge from these levels (Robinson). The following remarkable result was obtained: when the exciting radiation is a little harder than that of the hardest $L$-absorption edge $\left(L_{\mathrm{I}^{-}}\right)$, then the levels $L_{\mathrm{II}}$ and $L_{\mathrm{II}}$ give much more intense lines than the level $L_{\mathrm{I}}$. With increasing frequency, however, this relation is totally changed in favour of $L_{\mathrm{l}}$. With a frequency about five times as large as that of the $L$-edges, $L_{\mathrm{I}}$ is excited to a much larger extent than $L_{\mathrm{II}}$ and $L_{\mathrm{III}}$, so that the generally not very intense lines belonging to $L_{\mathrm{I}}$ become the most intense lines of the corpuscular $\beta$-ray spectrum in the experiments such as done by Robinson. This result points to the large influence of the quantum number $l$ (which is 1 for $L_{\mathrm{III}}$ and $L_{\mathrm{II}}$ and 0 for $L_{\mathrm{I}}$ ) on the excitation of the three $L$-sublevels.

It seemed to us worth while to try if a similar effect exists when the excitation is brought about by cathode rays of different velocities. The difficulty with such measurements is that the electrons which penetrate into the anticathode lose their velocity according to the Whiddington law, so that even when the $\mathrm{X}$-ray tube is operated with direct current a whole spectrum of velocities is obtained in the anti-cathode. We have tried to avoid this difficulty in the same manner as has been done for other purposes by Webster. A massive anticathode of beryllium with an extremely thin layer of tungsten was used and the three $L$-levels of tungsten were studied. The thickness of the tungsten was such that not more than 5 per cent of the energy of the cathode rays was absorbed by it. In this case, apart from small corrections, the relative intensities of the $\mathrm{X}$-ray lines coming from the three different $L$-levels give a good idea of the relative cathode ray excitation of these three $L$-levels. The lines $\beta_{2}\left(L_{\mathrm{III}}\right), \beta_{1}\left(L_{\mathrm{II}}\right)$ and $\beta_{3}\left(L_{\mathrm{I}}\right)$, which lie about in the same region of the spectrum, were used. When the tension varied from 15 to $40 \mathrm{kv}$., the line $\beta_{1}$ gets about 10 per cent more intense relative to $\beta_{2}$; the line $\beta_{3}$, however, gets about 30 per cent more intense relative to $\beta_{2}$. This result is the more interesting because for tungsten the energy difference $L_{\mathrm{II}}-L_{\mathrm{III}}$ is about 2.5 times as large as the difference $L_{\mathrm{I}}-L_{\mathrm{II}}$. It seems, therefore, that here, as in the case of the excita- 